http://jmscr.igmpublication.org/home/ ISSN (e)-2347-176x ISSN (p) 2455-0450

crossref DOI: https://dx.doi.org/10.18535/jmscr/v7i10.72

Journal Of Medical Science And Clinical Research

\title{
Assessment of dental caries among outdoor patients in a tertiary care hospital of Northern India
}

\author{
Authors
}

\author{
Dr Saurabh Singh ${ }^{1}$, Attiuddin Siddiqui ${ }^{2}$, Dr Bharat Bhushan ${ }^{3 *}$ \\ ${ }^{1}$ Associate Professor, Department of Dentistry, IIMSR Lucknow \\ ${ }^{2}$ Senior Resident Department of Dentistry, IIMSR \\ ${ }^{3}$ Associate Professor, Dental Department Govt Medical College Haldwani \\ *Corresponding Author \\ Dr Bharat Bhushan \\ Associate Professor, Dental Department Govt Medical College Haldwani, India
}

\begin{abstract}
Background and Objectives: Dental caries is an irretrievable disease, with a likelihood of new lesions that continue to affect humanity. Dental caries or tooth decay is an acquired chronic infective disease process caused by the acidic by-products of bacteria inhabiting organized dental plaque or oral bio-film that, if left uninterrupted, can dissolve or demineralize the enamel surfaces of the teeth. The aim of this study was to assess the dental caries and oral health status of the outdoor patients attending a tertiary care hospital of Northern India.

Materials and Methods: The present cross-sectional study was carried out in the Department of Dentistry, Integral Institute of Medical Sciences and Research, Lucknow, India. The study was carried out for a duration of six months from February 2019- July 2019. Data entry and management were carried out using MS excel spreadsheet and software.

Results: Out of total 3743 study subjects, 1775 (47.4\%) of the study subjects had dental caries. In females, $52.5 \%$ were having dental caries and $47.5 \%$ males were suffering with dental caries. Majority of study subjects belonged to the age group equal to or above 12 years, $94.2 \%$ of them had caries.

Conclusion: Despite scientific advances and the fact that it is a preventable disease, dental caries continues to be a major public health problem. Implementation of Primary prevention strategies is the need of the hour to reduce the burden of dental caries.

Keywords: Dental caries, oral health status, cross-sectional.
\end{abstract}

\section{Introduction}

Oral health is the most effective measure to prevent caries and periodontal disease. ${ }^{[1]}$ Dental caries is an irreversible disease, with a likelihood of new lesions that continue to affect humanity Dental caries or tooth decompose is an acquired chronic infective disease process caused by the acidic by-products of bacteria inhabiting organized dental plaque or oral bio-film that, if left undisturbed, can disband the enamel surfaces of the teeth. Despite marked developments in the oral health of children in many developed countries in the last 20-30 years, evidence suggests that a small proportion of children in such nations carry the highest dental caries load. ${ }^{[2]}$ It was long argued that certain races (such as Africans \& Asians) enjoy greater caries-resistance (compared to Europeans and Americans). Nevertheless, today it is believed that an environment with its typical culture, 
socioeconomic status, life style and dietary blueprint can have a greater impact on caries confrontation or expansion than the so-called inherent racial attributes. ${ }^{[3,4]}$ Dental caries and periodontal diseases are the main oral health troubles and indicators of oral health load all over the world. ${ }^{[5,6]}$ Though the prevalence of dental caries varies globally, it is believed that the disease has a high prevalence, wide geographic spread, and graded severity. ${ }^{[5-7]}$ The impact of the disease on the financial system and the quality of life of people make it a health condition of public attention. ${ }^{[6],[8]}$ The World Health Organization (WHO) recommends epidemiological studies on 35-44 years and 65-74 years age groups due to their relevance in describing and analyzing the cumulative damage of caries on people's oral health over the years. ${ }^{[8]}$ Information from these adult population groups is also used to generate evidence on final outcomes of dental care delivered to people during their entire life cycle. ${ }^{[9]}$ Recent epidemiological reports suggest that there is resurgence in the scourge of dental caries in the developed countries, where the disease had hitherto been considerably controlled. ${ }^{[10],[11]}$ In the developing countries, Though, studies have consistently shown that the load of oral diseases such as caries and periodontal diseases is rising. ${ }^{[12]}$ The present study was undertaken to assess the incidence of dental caries and oral health status of the outdoor patients attending the dentistry department of a tertiary hospital situated in northern India.

\section{Material and Methods}

The present cross sectional study was carried out in the Department of Dentistry, Integral Institute of Medical Sciences and Research, Lucknow, India. The study was carried out for a duration of six months from February 2019- July 2019. Clearance for examination of subjects was taken from the Immediate In-charge of the Department of Dentistry and a verbal informed consent was acquired from the subjects prior to the examination. All those subjects who were not able to give a consent for themselves because of age and cognition, a proxy consent was acquired from the attendant or accompanying person. A simple random sampling method was utilized for collection of the samples. All those subjects who visited the departmental OPD in the study time frame were included in the study. Inclusion criteria comprised of a positive consent by the subjects, subjects without any physical or mental disability. The subjects with a history of trauma, or patients wearing orthodontic appliances or any prosthesis were excluded from the study. The respondents were interviewed personally by the investigator to get first-hand information as well as the real picture of their oral health status through direct observation. All subjects were explained about the study. Dental examination was done in the Department of Dentistry by dental diagnostic sets (mouth mirror, sickle explorer), personal protective barriers (gloves, masks) and cotton roll. Examination for dental caries was carried out with a plane mouth mirror \& a sickle explorer in a systematic orderly fashion using the FDI tooth-numbering system, hence proceeding from one tooth or tooth space to another, starting at upper right 17 in upper arch around to upper left 27 , then beginning the lower arch at lower left 37 around to lower right 47.

\section{Ethical Consideration}

The study was approved by the Institutional Research Committee \& the Institutional Ethics Committee.

\section{Statistical Analysis}

Data entry and management were carried out using MS excel spreadsheet and software. A result was analyzed by calculating descriptive statistics. Data were presented in number, percentage graphs.

\section{Results}

The study comprised of 3743 study subjects attending the Outpatient department of Dentistry, Integral Institute of Medical Sciences and Research, Lucknow. 
Figure 1: Distribution of patients with dental caries with respect to sex

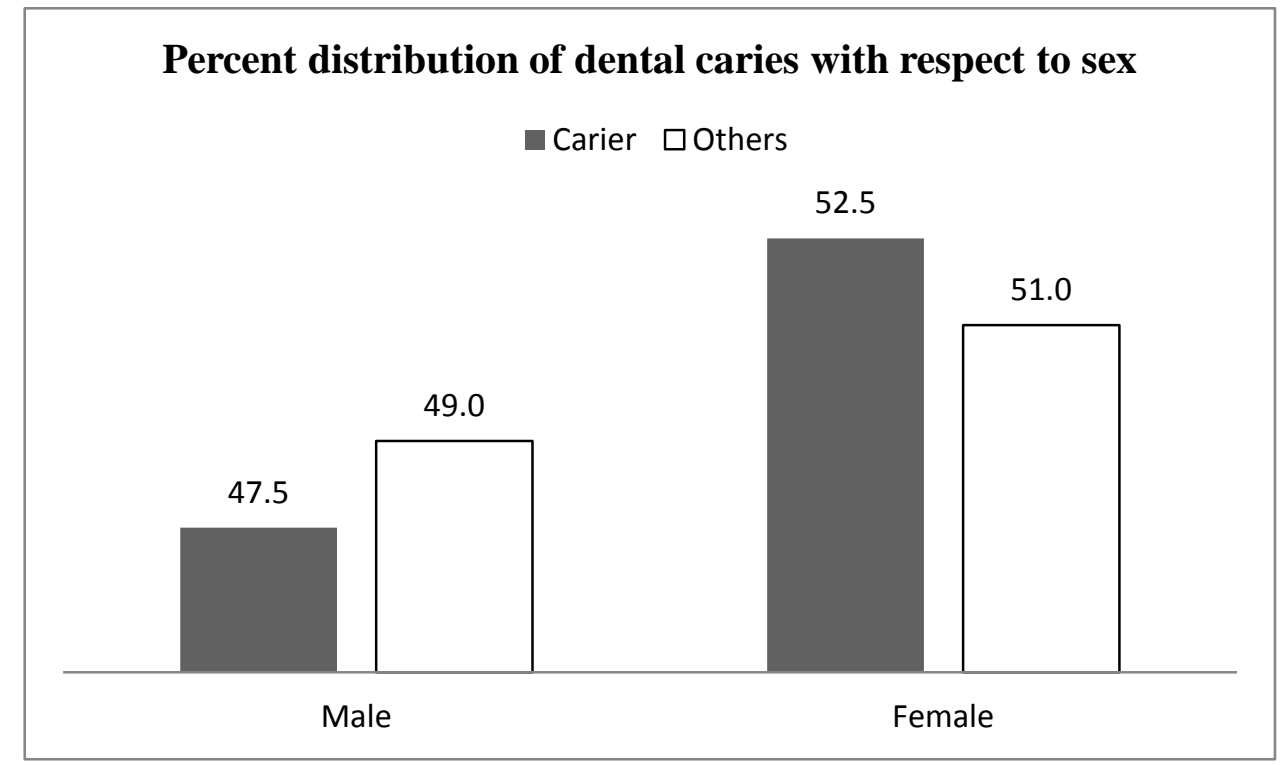

Figure1 illustrates that the frequency distribution of study subjects with respect to dental caries and other dental diseases. Out of total of 3743 study subjects, 1936 were females and 1807 were males. In females, $52.5 \%$ were having dental caries disease and $51 \%$ had other diseases. On the other hand, $47.5 \%$ males were suffering with dental caries disease. Percentage of dental caries disease was high among females as compared to males. (figure 1)

Figure 2: Percent distribution of dental caries with respect to age

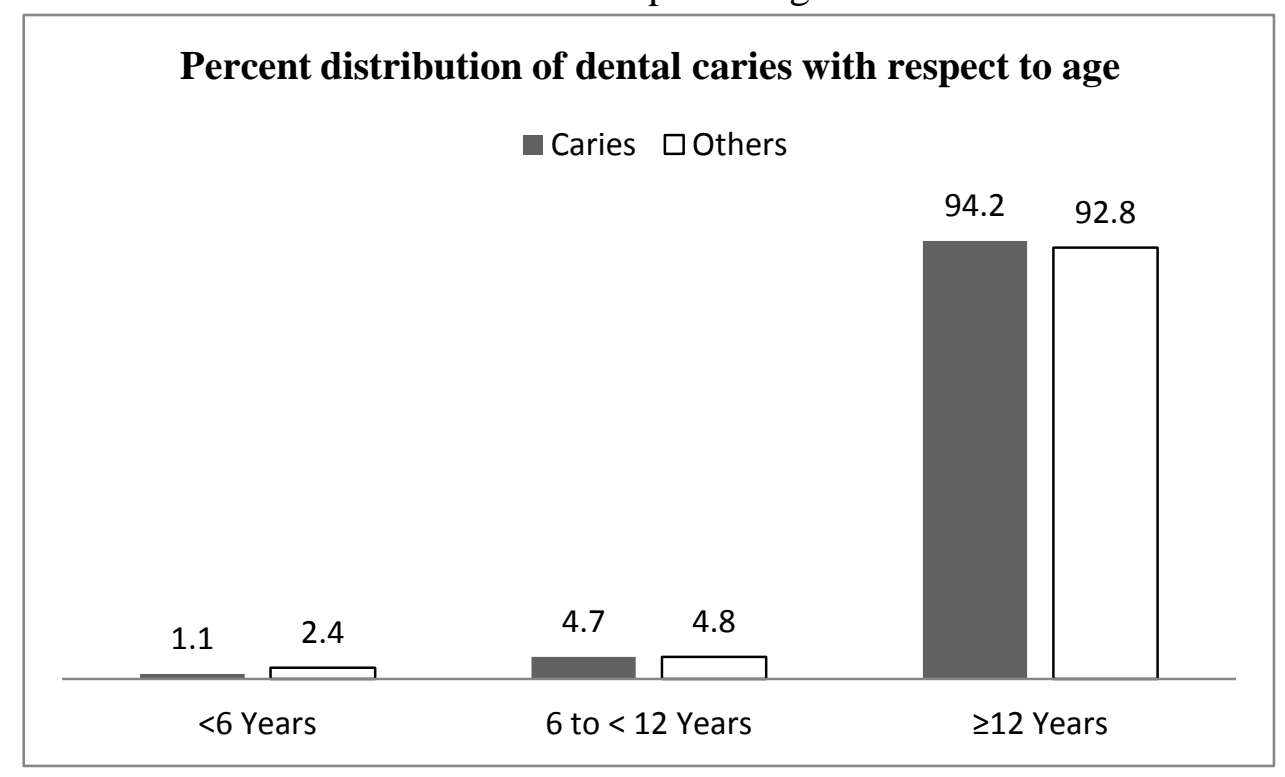

Majority of study subjects were belonging to age group equal to or above 12 years. In this group $94.2 \%$ of study subjects had dental caries disease. In age group 6 to less than 12 years, only $4.7 \%$ had dental caries disease. Only $1.1 \%$ study subjects who belonged to less than 6 years had dental caries disease. (Figure 2) 
Table 1: Month wise distribution of dental caries patients with respect to age-sex

\begin{tabular}{|c|c|c|c|c|c|c|c|c|c|c|c|c|}
\hline & \multicolumn{2}{|c|}{ February } & \multicolumn{2}{|c|}{ March } & \multicolumn{2}{|c|}{ April } & \multicolumn{2}{|c|}{ May } & \multicolumn{2}{|c|}{ June } & \multicolumn{2}{|c|}{ July } \\
\hline & No. & $\%$ & No. & $\%$ & No. & $\%$ & No. & $\%$ & No. & $\%$ & No. & $\%$ \\
\hline \multicolumn{13}{|l|}{ Sex } \\
\hline Male & 131 & 15.5 & 117 & 13.9 & 157 & 18.6 & 140 & 16.6 & 121 & 14.4 & 177 & 21.0 \\
\hline Female & 164 & 17.6 & 194 & 20.9 & 169 & 18.1 & 124 & 13.3 & 113 & 12.1 & 168 & 18.0 \\
\hline \multicolumn{13}{|l|}{ Age } \\
\hline$<6$ Years & 0 & 0 & 7 & 36.8 & 3 & 15.8 & 5 & 26.3 & 2 & 10.5 & 2 & 10.5 \\
\hline 6 to $<12$ Years & 14 & 16.7 & 8 & 9.5 & 15 & 17.9 & 11 & 13.1 & 20 & 23.8 & 16 & 19.0 \\
\hline$\geq 12$ Years & 281 & 16.8 & 296 & 17.7 & 308 & 18.4 & 248 & 14.8 & 212 & 12.7 & 327 & 19.6 \\
\hline
\end{tabular}

Table 1 shows monthly distribution of dental caries with respect to age-sex, Incidence of male subjects was highest in the month of July i.e., 21.0\%. Followed by April i.e., 18.6\%. Whereas, Incidence of female subjects was highest in the month of March i.e., 20.9\%. Followed by April i.e., 18.1\%.Table also represents incidence of dental caries diseases with respect to age group, Majority of study subjects were belonging to age group equal to or above 12 years. In this group 1672 study subjects had dental caries disease. In age group 6 to less than 12 years, 84 had dental caries disease. Only 19 subjects belong to age group less than 6 years, in which maximum incidence of dental caries in the month of March. (Table 1)

Table 2: Incidence of dental diseases in study subjects

\begin{tabular}{|l|c|c|}
\hline Disease & Incidence (No.) & \% \\
\hline Dental Caries & 1775 & 47.4 \\
\hline Others & 1968 & 52.6 \\
\hline Total & 3743 & 100.00 \\
\hline
\end{tabular}

Out of total 3743 study subjects, approximately one half of the study subjects had dental caries disease. Approximately equal numbers of the study subjects were suffering with other diseases/problems such as periodontal, bad breath, tooth decay, oral cancer, mouth sores, tooth erosion, tooth sensitivity and toothaches. (Table 2)

\section{Discussion}

Poor oral health impacts a great deal on the quality o life of children, adults, and the aged. It affects children nutrition, growth, and development. In adults, routine daily activities may be disrupted leading to considerable economicloss. ${ }^{[13,14]}$ Good oral health is beyond good dentition; it includes absence of pain, diseases, or any disorders of the dentofacial region and oral cavity. ${ }^{[15]}$ Gender is a major determinant of oral health status. The result of this study showed that males had considerable better oral health status than females. This finding is in disagreement with that of other studies. ${ }^{[16-19]}$ In support of present study Lukacs et al explained that, when dental caries rates are reported by sex, females are typically found to exhibit higher prevalence rates than males. Caries rates for females $(8.8 \%, 158 / 1,790)$ are approximately twice the frequency of caries among males $(4.5 \%$, 68/1,498). Higher caries prevalence among females is often explained by one of three factors: 1) earlier eruption of teeth in girls, hence longer exposure of girls' teeth to the cariogenic oral environment, 2) easier access to food supplies by women and frequent snacking during food preparation, and 3) pregnancy. Anthropologists tend to favor explanations involving behavior, including sexual division of labor and women's domestic role in food production. ${ }^{[20]}$ A study conducted on age between 5 and 12-year-old children. In the 5-year-old age group, $47.4 \%$ of those children with caries were male, while $41.1 \%$ of those children were female. However, in the 12-year-old age group a greater percentage of those children with caries were female $(24.1 \%$ female versus $20.6 \%$ male). ${ }^{[21]}$ WHO reported 60 $90 \%$ of school children worldwide has experienced caries with the disease being most prevalent in Asian and Latin American countries. ${ }^{[22]}$ Moreover, in present study majority of study subjects were belonging to age group equal to or 
above 12 years. In age group 6 to less than 12 years, only $4.7 \%$ had dental caries disease. Olabisi et $\mathrm{al}^{[23]}$ included mean age in their study was comparable to $34.9 \pm 14.2$ years reported in a similar epidemiologic study on oral health status among adult subjects in a rural community in India. ${ }^{[2]}$ In present study, approximately fifty percent of the study subjects had dental caries disease. This result was near about similar to studies reported by Rao et al who reported prevalence of $76.9 \%$ among 5-12 year olds. ${ }^{[25]}$ and Shingare et al who reported prevalence of $80.92 \%$ among 3-14 years old. ${ }^{[26]}$ Similar high caries prevalence was found in studies done in Mangalore city by Sudha $\mathrm{P}^{[27]}$ et al $82.5 \%$. In a study done in the Sunder bans, the caries prevalence was $82 \%$ and it increased with age. ${ }^{[28]}$ However, the prevalence lower in studies by Misra and Shee ${ }^{[29]} 60.41 \%$ and Chopra et al. ${ }^{[30]}$ $61.88 \%$.

\section{Conclusion}

Despite scientific advances and the fact that it is a preventable disease, dental caries continues to be a major public health problem. The consistent trend of caries rates being higher in females than males is still not understood. Further research is needed to identify and understand the role of factors contributing in the development of dental caries in women and to anticipate the disease process before it begins. Implementation of Primary prevention strategies is the need of the hour to reduce the burden of dental caries.

\section{References}

1. Choo A, Delac DM, Messer LB. Oral hygiene measures and promotion: review and considerations. Aust Dent J., 2001; 46(3): 166-173.

2. Harris R, Nicoll AD, Adair PM, Pine CM. Risk factors for dental caries in young children: a systematic review of the literature. Community Dental Health, 2004; 21 : 71-85.
3. Brian AB, Stephen AE. Dentistry, Dental Practice and the Community. 5th edition, 1999, P. 217-224.

4. Murray JJ. Prevention of Oral Disease. 3 rd edition, 1996, p. 3 \& 231.

5. Thorpe S. Oral health issues in the African region: Current situation and future perspectives. J Dent Educ 2006;70 Suppl 1:8-15.

6. Omitola OG, Arigbede AO. Prevalence of dental caries among adult patients attending a tertiary dental institution in south-south region of Nigeria. Port Harcourt Med J 2012;6:52-8.

7. Naito M, Yuasa H, Nomura Y, Nakayama T, Hamajima N, Hanada N. Oral health status and health-related quality of life: A systemic review. J Oral Sci 2006;48:1-7.

8. Urzua I, Mendoza $\mathrm{C}$, Arteaga $\mathrm{O}$, Rodríguez G, Cabello R, Faleiros S, et al. Dental caries prevalence and tooth loss in Chilean adult population: First national dental examination survey. Int $\mathrm{J}$ Dent 2012;2012:810170

9. Petersen PE. Priorities for research for oral health in the 21st century-the approach of the WHO Global Oral Health Programme. Community Dent Health 2005;22:71-4.

10. Bagramian RA, Garcia-Godoy F, Volpe AR. The global increase in dental caries. A pending public health crisis. Am J Dent 2009;22:3-8.

11. Marthaler TM. Changes in dental caries 1953-2003. Caries Res 2004;38:173-81.

12. Agbelusi GA, Jeboda SO. Oral health status of 12-year-old Nigerian children. West Afr J Med 2006;25:195-8.

13. Choo A, Delac DM, Messer LB. Oral hygiene measures and promotion: review and considerations. Aust Dent J., 2001; 46(3): 166-173.

14. Harris R, Nicoll AD, Adair PM, Pine CM. Risk factors for dental caries in young children: a systematic review of the 
literature. Community Dental Health, 2004; 21: 71-85.

15. Brian AB, Stephen AE. Dentistry, Dental Practice and the Community. 5th edition, 1999, P. 217-224.

16. Bratthall D. Introducing the Significant Caries Index together with a proposal for a new oral health goal for 12-year-olds. Int Dent J., 2000; 50: 378-84.

17. Saravanan S, Kalyani V, Vijayarani MP, Jayakodi P, Felix J, Arunmozhi P, Krishnan V, Sampath Kumar P. Caries prevalence and treatment needs of rural school children in Chidambaram Taluk, Tamil Nadu, South India. Indian J Dent Res., 2008; 19(3): 186-90.

18. Rai B, Jain R, Kharb S, Anand S.C: Dental Caries And Oral Hygiene Status of 8 To 12 Year School Children Of Rohtak: A Brief Report. The Internet Journal of Dental Science, 2007; 5(1): 13.

19. Gibson S, Williams S. Dental caries in preschool children: associations with social class, tooth brushing habit and consumption of sugars and sugar containing foods. Further analysis of data from the National Diet and Nutrition Survey of children aged 1.5-4.5 years. Caries Res., 1999; 33(2): 101-13

20. Lukacs JR, Largaespada LL. Explaining sex differences in dental caries prevalence: saliva, hormones, and "life-history" etiologies. Am J Hum Biol. 2006 JulAug;18(4):540-55.

21. Saravanan S, Anuradha KP,Bhaskar DJ, Prevalence of dental caries and treatment needs among school going children of Pondicherry, India, Journal of the Indian Society of Pedodontics and Preventive Dentistry, 2003;21(1):1-12.

22. Prasai Dixit L, Shakya A, Shrestha M, Shrestha A. Dental caries prevalence, oral health knowledge and practice among indigenous Chepang school children of Nepal. BMC Oral Health, 2013; 13:20.
23. Olabisi AA, Udo UA, Ehimen UG, Bashiru BO, Gbenga OO, Adeniyi AO. Prevalence of dental caries and oral hygiene status of a screened population in Port Harcourt, Rivers State, Nigeria. J Int Soc Prevent Communit Dent 2015;5:59-63

24. Maru AM, Narendran S. Epidemiology of dental caries among adults in a rural area in Indian. J Contemp Dent Pract 2012;13:382- 8 .

25. Rao A, Sequeira SP, Peter S. Prevalence of dental caries among school children of Moodbidri. J Indian Soc PedodPrev Dent. 1999; 17:45-8.

26. Shingare P, Jogani V, Sevekar S, Patil S, Jha M. Dental caries prevalence among 314 year old school children, Uran, Raigad district, Maharastra. Journal of Contemporary Dentistry. 2012; 2(2):1114.

27. Sudha P, Bhasin S, Aneguni RT. Prevalence of dental caries among 5-13 year-old children of Mangalore city. J Indian Soc PedodPrev Dent. 2005; 23(2):74-79.

28. Datta P, Datta PP. Prevalence of Dental Caries among School Children in Sundarban, India. Epidemiol. 2013; 3:135.

29. Misra FM, Shee BK. Prevalence of dental caries in school going children in an urban area of South Orissa. J Indian Dent Assoc. 1979; 51:267-70.

30. Chopra S, Vacher BR, Taneja JR. Dental Caries experience during the period of mixed dentition. J Indian Dent Assoc. 1983; 55(3):99-104. 